\title{
Strategi Marketing Public Relations PT Lotte Indonesia dalam Memperingati Hari Ibu
}

\author{
Robbikal Muntaha Meliala ${ }^{1}$ \\ Fakultas Komunikasi dan Bahasa, Universitas Bina Sarana Informatika \\ Email: robbikal.rtl@bsi.ac.id
}

\begin{abstract}
ABSTRAK
PT Lotte Indonesia adalah perusahaan multinasional yang memproduksi makanan ringan di Indonesia sejak 1993. Namun perusahaan ini berpusat di Jepang dan sudah didirikan sejak 1948. Salah satu produksi makanan ringannya adalah biskuit coklat "Lotte Choco Pie". Fungsi kehumasan di perusahaan ini dijalankan oleh Manajer Marketing yang juga membawahi Departemen Sales, sehingga kegiatan marketing pada perusahaan ini tidak hanya melakukan fungsi "business to business" saja namun melakukan kegiatan bauran public relations juga, sehingga konsep Marketing Public Relations berlaku pada penelitian ini. Upaya marketing public relations PT Lotte Indonesia akhir-akhir ini adalah menyelenggarakan acara spesial "Lotte Choco Pie Idol 2020". Kegiatan ini sejenis pencarian bakat pada kompetisi menyanyi yang ditujukan pada anak anak berusia 6-12 tahun dimana diwajibkan untuk menyanyikan lagu bertema "ibu" dan divideokan lalu diunggah di Youtube pada periode 26 November 2020 hingga 12 Desember 2020. Acara grand final dilakukan pada 20 Desember 2020 sekaligus mengumumkan untuk 3 peserta terbaik dan beragenda seminar tentang kenali potensi anak yang menghadirkan psikolog anak, Rininta Meyftonaria. Metode Penelitian: Penelitian berpendekatan kualitatif deskriptif dengan observasi, wawancara, studi pustaka dan dokumentasi sebagai teknik pengumpulan data. Kesimpulan: PT Lotte Indonesia berhasil mengadakan acara khusus pada masa pandemic covid 19 dengan menggunakan jasa konsultan humas "Jeune \& Raccord" dengan bauran sistem tatap muka dan dalam jaringan internet. Lotte Choco Pie Idol 2020 terpilih adalah Lawrence Oktavianus, mendapat hadiah 10 Juta Rupiah dan Single terbaru berjudul "My Supermom". PT Lotte Indonesia berhasil mengimplementasikan strategi pull dan pass marketing public relations untuk mempromosikan Lotte Choco Pie sebagai merek produk yang mengutamakan kedekatan ibu dan anak.
\end{abstract}

Kata-kata Kunci: Acara Khusus, Marketing Public Relations, Strategi

\section{Marketing Public Relations Strategy of PT Lotte Indonesia in Commemorating Mother's Day}

\begin{abstract}
PT Lotte Indonesia is a multinational corporate who produced variant snacks in Indonesia since 1993. But, this corporate has been centered in Japan and already established since 1948. One of their snack is chocolate biscuit of Lotte Choco Pie. The functional of Lotte's Public Relations has been organized by Marketing manager which also controlled Sales Department, so that marketing activities in this corporate not only focuses on "business to business" activities but also mixture of public relations activities indeed. Therefore Marketing Public Relations concept will be valid to be described by author in this research. Efforts of marketing public relations of PT Lotte Indonesia recently is conducted special event "Lotte Choco Pie Idol 2020". This event such as singing competition or talent search which referred to children in age of 6 until 12 years old. The contestants should sing a special song in mothers themed and had been recorded by video camera and uploaded those in youtube for period
\end{abstract}


November, 26 till December 12, 2020. Grand Final show was held on December 20, 2020 then will be announced 3 best contestants and at the same time with another agenda is national seminar about how to know and find children potential who had been presented by children psychologist, Rininta Meyftonaria. Research method: Descriptive Qualitative with observation, interview, study of literature and documentation as techniques of data collecting. Conclusion : PT Lotte Indonesia has succeed to conduct special events in pandemic of covid 19 time by used and hired public relations consultant "Jeune \& Raccord" with mixture of offline event and online activities (in internet connection). Lotte Choco Pie Idol 2020 is Lawrence Oktavianus who was chosen as first winner and got 10 million rupiahs and also got first single song who titled "My Supermom". PT Lotte Indonesia has succeed to promote Lotte Choco Pie's brand who prioritized emotional chemistry between mom and her children.

Keywords: Special Event, Marketing Public Relations, Strategy

\section{PENDAHULUAN}

Makanan adalah kebutuhan pokok manusia. Beragam perusahaan makanan hadir di Indonesia baik perusahaan nasional maupun perusahaan multinasional. Salah satu perusahaan multinasional yang hadir di Indonesia dalam memproduksi makanan ringan kepada masyarakat adalah PT Lotte Indonesia. Perusahaan ini sebenarnya berpusat di Jepang dan didirikan sejak tahun 1948. Perusahaan ini terus berekspansi hingga ke 11 negara diantaranya Vietnam, Philipina, USA, India, Singapura, Taiwan, Polandia, Indonesia, Rusia dan China. PT Lotte Indonesia sendiri berdiri sejak 1993 dengan produk makanan ringan seperti biskuit, biskuit coklat dan permen karet. Salah satu merek produk biskuit coklat yang diproduksinya adalah Lotte Choco Pie.

Fungsi kehumasan perusahaan PT Lotte Indonesia dijalankan oleh Manajer
Marketing. Manajer Marketing ini juga membawahi Departemen Sales atau Penjualan, sehingga aktivitas Marketing di perusahaan ini tidak berfokus hanya pada "business to business" saja tapi juga bauran aktivitas public relations atau kehumasan lainnya. Kegiatan marketing public relations adalah sebutan paling tepat yang dilakukan oleh Manajer Marketing PT Lotte Indonesia.

Menurut Harris (Soemirat, S. dan Ardianto, 2016) mendefinisikan Marketing Public Relations merupakan proses dari perencanaan, pelaksanaan dan evaluasi program-program yang mendorong minat beli serta kepuasan konsumen, melalui penyampaian informasi dan kesan yang meyakinkan, dalam usaha memperlihatkan bahwa perusahaan dan produk-produknya sesuai dengan kebutuhan, keinginan, kepentingan, dan minat konsumen.

Berdasarkan pengertian tersebut, kita dapat mengetahui bahwa pekerjaan dari Manajer Marketing PT Lotte 
Indonesia tidaklah mudah. Tanggung jawabnya tidak hanya bertanggung jawab pada aktivitas kehumasan murni saja, tapi juga bagaimana mendorong minat beli serta kepuasan konsumen melalui strategi dan tak-tik tertentu. Pada referensi lain juga dinyatakan :

Menurut Vanessa (Hidayat, 2015) Marketing Public Relations merupakan komunikasi yang dapat dipercaya untuk menjembatani perusahaan dengan konsumennya dengan tujuan menambah nilai pelanggan dan merangsang pembelian serta kepuasan konsumen dan sekaligus membentuk kesan terhadap perusahaan.

Pada referensi ini, penulis memahami bahwa upaya marketing public relations juga harus tampil sebagai penjembatani antara perusahaan dan konsumennya dan memberi nilai tambah bagi pelanggan atas produk yang dipasarkan dan dijualnya. Nilai tambah tersebut perlu dikomunikasikan dan dievaluasi serta dibentuk dalam suatu program. Program yang dibuat harus merangsang penjualan dan pelanggan. Hal ini senada dengan apa yang diungkapkan:

\section{Marketing Public Relations}

(MPR) merupakan penggabungan fungsi marketing dengan fungsi public relations. Marketing Public Relations menurut Thomas L. Haris adalah, "Sebuah proses perencanaan, pelaksanaan dan pengevaluasian program-program yang merangsang penjualan dan pelanggan. Hal tersebut dilakukan melalui pengkomunikasian informasi yang kredibel dan kesan-kesan yang dapat menghubungkan perusahaan, produk dengan kebutuhan serta perhatian pelanggan.” Ruslan dalam (Ihsan, 2018).

Program yang dibuat juga menggunakan prinsip dari bauran public relations, yang dibuat tidak dapat dengan mendadak, namun harus terencana (well organized) dan paham siapa khalayak yang organisasi tuju dan hadapi.

Menurut Rhenald Kasali dalam (Ali, 2017), "Khalayak Marketing Public Relations adalah masyarakat dan konsumen. Berdasarkan pendapat tersebut, marketing public relations dapat diartikan sebagai pengelolaan komunikasi untuk memotivasi pembelian, dan kepuasan pelanggan,konsumen, dan masyarakat.

Upaya marketing public relations dalam membuat suatu program harus disertai dengan strategi dan tak-tik yang baik. Esensi itulah yang menggiring setiap praktisi organisasi memanfaatkan momentum tertentu dengan sentuhan logika dan emosional.

Menurut Cutlip dalam (Mayasari, S., Purihastine, M., dan Qibtiah, 2019) mendefinisikan "Strategi sebagai penentuan tujuan dan sasaran dasar jangka panjang suatu perusahaan dan 
pengalokasian sumber daya yang perlu untuk melaksanakan cita - cita ini."

Sementara menurut Menurut Nanang Fattah \& H. Mohammad Ali dalam (Arifin, 2017), "Mendefinisikan strategi sebagai pemikiran secara konseptual, realistis dan komprehensif tentang langkah-langkah yang diperlukan untuk mencapai tujuan dan sasaran yang telah ditetapkan. Sementara tak-tik adalah bentuk khusus dari strategi yang sudah direncanakan dan diterjemahkan konseptor sebagai langkah konkret yang membantu strategi dapat berjalan lancar dan optimal".

Hari ibu yang dirayakan pada setiap 22 Desember secara nasional merupakan momentum yang dimanfaatkan oleh PT Lotte Indonesia. Hari ibu ini dianggap sebagai waktu yang tepat bagi PT Lotte Indonesia untuk mempromosikan produk Lotte Choco Pie dengan filosofi membangun kedekatan (bounding) antara ibu dan anak. Berdasarkan pantauan penulis melalui official website http://lotte.co.id/id/home dan wawancara pendahuluan dengan key informan yaitu Ingen Ate Malem Meliala, momentum ini sejalan dengan branding Lotte Choco Pie yang gencar mengedukasi masyarakat tentang pentingnya kedekatan ibu dengan anak dan membangun suasana keluarga yang baik bersama dengan santapan biskuit coklat Lotte Choco Pie di saat senggang.
Berbicara tentang strategi marketing public relations, Thomas L. Harris dalam bukunya yang berjudul The Marketer's Guide to Public Relations in the 21th Century, yang diterjemahkan penulis membagi dalam 3 bentuk yaitu:

1. Push Strategy (Strategi Mendorong) yaitu strategi yang menggunakan tenaga penjualan atau bagian promosi perdagangan untuk mendorong produk melalui saluran distribusi. Para produsen secara agresif mempromosikan produk ke pedagang besar (distributor). Kemudian, distributor mempromosikan produk secara agresif kepada pedagang kecil (retail): dan pedagang kecil mempromosikan produk kepada konsumen.

2. Pull Strategy (Strategi Menarik) yaitu strategi yang menarik dan dianggap menghabiskan banyak uang untuk periklanan dan promosi kepada konsumen, untuk membangun permintaan kepada konsumen. Jika strategi ini efektif, konsumen akan mengajukan permintaan produk kepada pedagang kecil (retail), pedagang kecil akan mengajukan permintaan produk ke pedagang besar (distributor) dan pedagang besar (distributor) akan mengajukan permintaan produk kepada produsen. 
3. Pass Strategy (Strategi Melewati) yaitu strategi dengan menggunakan dua komponen kekuatan corporate public relations karena menyadari situasi masyarakat kini semakin kompleks. Hal ini memungkinkan pemasar untuk memperoleh kesempatan dari para pemuka pendapat atau pihak yang berwenang dalam memasuki pasar tertentu dan untuk mengatasi isu-isu publik dalam rangka menetralisir pertentangan atau persaingan (Harris, 2016).

Jika dikaitkan dengan penelitian ini, maka Manajer Marketing PT Lotte Indonesia dapat memilih jenis strategi marketing public relations sebelum membuat suatu program. Terdapat 3 pilihan strategi sesuai dengan tujuannya yaitu Push Strategy (Strategi Mendorong), Pull Strategy (Strategi Menarik) dan Pass Strategy (Strategi Melewati).

Menurut Cutlip-Center-Broom dalam (Trisnawati, A. dan Syarah, 2017) menyimpulkan bahwa, "Ruang lingkup public relations mencakup publisitas, pemasaran, public affairs, manajemen isu, lobi, dan hubungan investor."

Berikut strategi PENCILS dalam Marketing Public Relations :

1. Publication (Publikasi)

Setiap fungsi dan tugas public relations adalah menyelenggarakan publikasi atau menyebarluaskan informasi melalui berbagai media tentang aktivitas atau kegiatan perusahaan atau organisasi yang pantas untuk diketahui oleh publiknya. Setelah itu, menghasilkan publisitas untuk memperoleh tanggapan positif secara luas dari masyarakat.

2. Event (Penyusunan Program Acara) Merancang acara tertentu atau lebih dikenal dengan peristiwa (special event) yang dipilih dalam jangka waktu, tempat, dan objek tertentu yang khusus sifatnya untuk mempengaruhi opini publik.

3. News (Menciptakan Berita)

Berupaya menciptakan berita melalui press release, newsletter dan bulletin dan lain-lain yang biasanya mengacu teknis penulisan $5 \mathrm{~W}+1 \mathrm{H}$ dengan sistematika penulisan "piramida terbalik", yang paling penting menjadi lead atau intro dan dan kurang penting diletakkan di tengah batang berita. Untuk itulah secara public relations, mau tidak mau harus mempunyai kemampuan untuk menulis, karena sebagian besar tugasnya untuk tulismenulis, khususnya dalam menciptakan publisitas.

4. Community Involvement (keperdulian kepada komunitas)

Keterlibatan tugas sehari-hari seorang public relations adalah mengadakan kontak sosial dengan kelompok 
masyarakat tertentu untuk menjaga hubungan baik dengan pihak organisasi atau lembaga yang yang diwakilinya.

5. Inform or Image (memberitahukan dan meraih citra)

Ada dua fungsi utama dari Public Relations, yaitu memberitahukan sesuatu kepada publik atau menarik perhatian, sehingga diharapkan akan memperoleh tanggapan berupa citra positif dari suatu proses "nothing" diupayakan menjadi "something". Dari yang tidak tahu menjadi tahu, setelah tahu menjadi suka, dan kemudian diharapkan timbul sesuatu (something) yang berupa citra.

6. Lobby or Negotiation (Pendekatan dan Bernegosiasi)

Keterampilan untuk melobi secara pendekatan pribadi dan kemampuan bernegosiasi sangat diperlukan bagi seorang public relations. Tujuan lobi adalah untuk mencapai kesepakataan (deal) atau memperoleh dukungan dari individu dan lembaga yang berpengaruh terhadap kelangsungan bisnis dan perusahaan.

7. Social Responsibility (Tanggung Jawab Sosial)

Memiliki tanggung jawab sosial dalam aktivitas Public Relations menunjukkan bahwa perusahaan memiliki kepedulian terhadap masyarakat. Hal ini akan meningkatkan citra perusahaan di mata publik. Saat ini banyak perusahaan menjadikan kegiatan sosial sebagai aktivitas yang harus dilakukan. Bentuknya beragam seperti peduli banjir, memberikan beasiswa, santunan anak yatim, pengobatan gratis, dan masih banyak kegiatan lainnya.

Wawancara pendahuluan yang dilakukan penulis kepada key informan yaitu Ingen Ate Malem Meliala selaku Manajer Marketing PT Lotte Indonesia mendapatkan hasil bahwa peringatan hari ibu pada 2020 ini akan dimeriahkan dengan special event berupa Lotte Choco Pie Idol 2020 dan Seminar dalam bentuk Jaringan (Webinar) tentang Kenali Diri dan Potensi Anak oleh Psikolog anak, ibu Rininta Meyftonaria. Lotte Choco Pie Idol adalah kegiatan pencarian bakat atau kompetisi menyanyi pada anak usia di rentang 6 hingga 12 tahun, yang sebenarnya sudah dilakukan rutin dari tahun 2018. Tahun 2020 ini akan berbeda karena situasi pandemi covid 19 pada dunia. Kebijakan ini sudah diumumkan World Health Organization (WHO) pada awal Maret 2020, termasuk Indonesia sehingga ruang lingkup mobilitas masyarakat menjadi terbatas karena adanya kebijakan Pembatasan Sosial Berskala Besar (PSBB) dan Protokol Kesehatan. 
Sementara, di sisi lain, ini menjadi tantangan tersendiri bagi tim Marketing PT Lotte Indonesia untuk tetap menyelenggarakan kegiatan khusus tersebut pada tahun 2020. Oleh karena itu, sistematika lomba menjadi berubah pada penilaian sistem dalam jaringan (internet). Periode lomba dimulai dari 26 November 2020 sampai dengan 12 Desember 2020 yang terdiri atas pendaftaran dan waktu para peserta untuk mengunggah video bernyanyi mereka ke youtube dengan mengusung satu lagu spesial bertemakan ibu. Babak penyisihan berlangsung dengan menyeleksi 10 video terbaik sebagai finalis dan nantinya mereka akan diundang pada acara grand final yang diadakan pada 20 Desember 2020. Pada 20 Desember 2020 tersebut diadakan juga webinar tentang kenali diri dan potensi anak bersamaan juga dengan pengumuman 3 terbaik yang menjadi juara Lotte Choco Pie Idol, dimana peserta webinar dapat menyaksikannya via Zoom Conference dan 10 finalis tadi bernyanyi dengan hadir secara fisik pada lokasi yang ditentukan panitia untuk Grand Final.

Menurut Mattews dalam (Virganantie, 2017) definisi dari special event adalah:

A special event is a ghatering of human beings, generally lasting from a few days, designed to celebrate, honor, discuss, sell, teach about, encouragare, observe, or influence human endeavors. Artinya adalah special event merupakan sebuah acara perkumpulan manusia, biasanya dalam jangka waktu beberapa jam atau beberapa hari, dirancang untuk merayakan, menghormati, membahas, menjual, mengajarkan sesuatu, mendukung, mengamati, atau mempengaruhi usaha manusia."

Jika dikaitkan dengan penelitian ini, maka PT Lotte Indonesia mengadakan acara perkumpulan manusia dalam waktu beberapa jam yang diorganisasikan pada hari tertentu yaitu merayakan hari ibu melalui kompetisi Lotte Choco Pie Idol 2020 dan Seminar dalam Jaringan (webinar) tentang perkembangan psikologi anak.

Menurut Goldblatt dalam (Hartono, N.A., Dida, S., dan Hafiar, 2017) mendefiniskan special event sebagai "unique moment in time celebrated with ceremony and ritual to satisfy specific needs." Special event adalah sebuah selebrasi yang dilaksanakan pada momen yang memiliki keunikan tertentu dengan bentuk seremonial dan ritual untuk memenuhi kebutuhan spesifik.

Sementara, jika dikaitkan dengan penelitian ini maka special event yang dibuat oleh PT Lotte Indonesia untuk merayakan momen unik tertentu, yaitu hari ibu. Hari ibu identik dengan hari spesial bagi anak untuk mengekspresikan 
rasa kasih sayang kepada ibu-nya dan mengistimewakan ibunda pada berbagai kegiatan. Lotte Choco Pie Idol 2020 ini merupakan kesempatan bagi anak mengekspresikan kasih sayang kepada ibunda dengan senandung lagu khusus bertemakan ibu.

(Ruslan, 2012) juga menyatakan bentuk-bentuk special events yang telah dikenal sebagai berikut ; Festival, Fair, Parade, Seminar dan Open House. Festival adalah kegiatan perlombaan seperti festival Musik Dangdut atau festival Paduan Suara Universitas Sejabodetabek. Seminar adalah pemaparan materi dari narasumber yang sudah ditentukan pada tema, waktu dan tempat khusus yang dilakukan secara internal, nasional maupun regional yang dikaitkan dengan peristiwa-peristiwa tertentu (istimewa).

Jika dikaitkan dengan penelitian ini, maka PT Lotte Indonesia mengadakan special event berbentuk Festival dan Seminar dalam memperingati hari Ibu tahun 2020. Kegiatan festival berupa Lotte Choco Pie Idol 2020 dan kegiatan seminar berupa webinar tentang kenali diri dan potensi anak yang dibawakan oleh narasumber psikolog anak yaitu Ibu Rininta Meyftonaria melalui aplikasi zoom conference pada 20 Desember 2020. Berawal dari latar belakang ini, maka penulis menemukan rumusan masalah yang akan dijawab dalam penelitian ini yaitu Evaluasi Special Event sebagai Strategi Marketing Public Relations PT Lotte Indonesia dalam Memperingati Hari Ibu.

\section{METODOLOGI}

Penelitian berpendekatan kualitatif deskriptif dipilih penulis dalam menemukan jawaban atas rumusan masalah yang sudah disebutkan pada bagian pendahuluan. Menurut Sudarwan Danim dalam Maulana, (2018) penelitian kualitatif memiliki ciri - ciri sebagai berikut: Sumber data lapangan langsung berupa data situasi alami dan peneliti adalah instrumen kunci, bersifat deskriptif, menekankan proses kerja analisis data bersifat induktif dan makna merupakan perhatian utama dalam pendekatan penelitian (H Maulana, 2018).

Selain itu, Furchan dalam (Linarwati, 2016) Penelitian deskriptif adalah penelitian yang dirancang untuk memperoleh informasi tentang status suatu gejala saat penelitian dilakukan. Dalam penelitian deskriptif tidak ada perlakuan yang diberikan atau dikendalikan serta tidak ada uji hipotesis sebagaimana yang terdapat pada penelitian eksperimen (Linawarti, M., 2016).

Teknik pengumpulan data yang dilakukan penulis berupa observasi, wawancara, studi pustaka dan dokumentasi. 
Pada tahap awal penulis melakukan observasi ke kantor pusat PT Lotte Indonesia yang beralamatkan di South Quarter Tower C, 3rd Floor, Jl. R.A. Kartini Kav.8

Cilandak Barat, Jakarta Selatan,12430. Observasi dilakukan pada awal Januari 2021 sekaligus untuk bertemu dengan Marketing Manager PT Lotte Indonesia dan melakukan wawancara mendalam.

Menurut Moleong dalam (Linawarti, M., 2016), menyimpulkan bahwa: "Wawancara adalah percakapan dengan maksud tertentu. Percakapan itu dilakukan oleh dua pihak, yaitu pewawancara (interviewer) yang mengajukan pertanyaan dan terwawancara (Interviewee) yang memberikan jawaban atas pertanyaan itu (Moleong, 2011)“.

Wawancara mendalam adalah proses memperoleh keterangan untuk tujuan penelitian dengan cara tanya jawab sambil bertatap muka antara pewawancara dengan responden atau orang yang diwawancarai, dengan tidak menggunakan pedoman guide wawancara dimana pewawancara dan informan terlibat dalam kehidupan sosial yang relatif lama. (Moleong, 2011).

Menurut Poerwandari dalam (Faradina, 2016), “Key informan adalah mereka yang mengetahui dan memiliki berbagai informasi pokok yang diperlukan dalam penelitian atau dilakukan secara berantai dengan meminta informasi pada orang yang telah diwawancarai atau dihubungi sebelumnya, demikian seterusnya" Sementara, menurut Hendarsono dalam (Sondak, Sandi Hesti, Rita, N, 2019), "Informan utama yaitu mereka yang terlibat secara langsung dalam interaksi sosial yang diteliti. Informan tambahan, yaitu mereka yang dapat memberikan informasi walaupun tidak langsung terlibat dalam interaksi sosial yang diteliti."

Penulis menjadikan Ingen Ate Malem Meliala sebagai Key Informan. Penulis menjadikan Indah Permata Sari sebagai Informan 1 sebagai konsumen produk Lotte Choco Pie dan peserta webinar. Lalu, penulis menjadikan Laila Zahira sebagai informan 2 sebagai konsumen produk Lotte Choco Pie dan peserta webinar. Penulis melakukan wawancara dengan informan 1 dan informan 2 melalui media sosial instagram dan whatsapp. Setelah wawancara dilakukan kepada semua narasumber dimulai key informan, informan 1 dan informan 2, penulis membuat transkrip wawancara dan rangkuman hasil wawancara diolah untuk menjawab dan mengisi tabel Analisis SWOT.

Menurut Rangkuti dalam (Udang et al., 2015,53) mengemukakan, "SWOT 
adalah singkatan dari lingkungan internal strengths dan weaknesses serta lingkungan eksternal Opportunities dan Threats yang dihadapi dunia bisnis. Analisis SWOT membandingkan antara faktor eksternal Peluang (Opportunities) dan Ancaman (Threats) dengan faktor internal kekuatan (Strengths) dengan kelemahan (Weaknesses)." (Udang, P., Pt, B., Mina, M., Aurora, N., Mustika, P.T., Nusa, M., Tarakan, A., dan Borneo, 2015)

\section{HASIL DAN PEMBAHASAN}

PT Lotte Indonesia berdiri di Indonesia sejak 1993. Perusahaan ini memproduksi variasi makanan ringan yang terdiri dari biskuit coklat, permen karet, stick biscuit dan aneka biskuit lainnya.

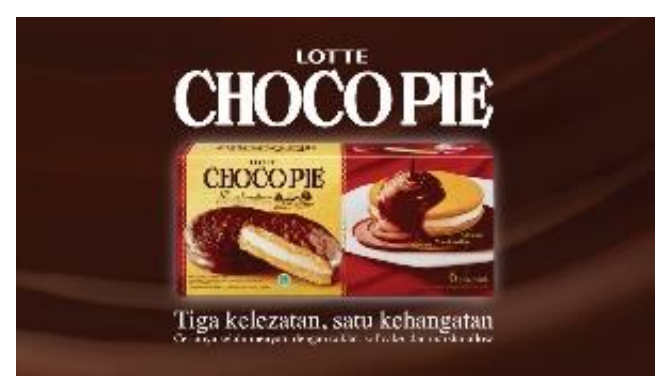

Gambar 1 Foto Produk Lotte Choco Pie (Biskuit Coklat)

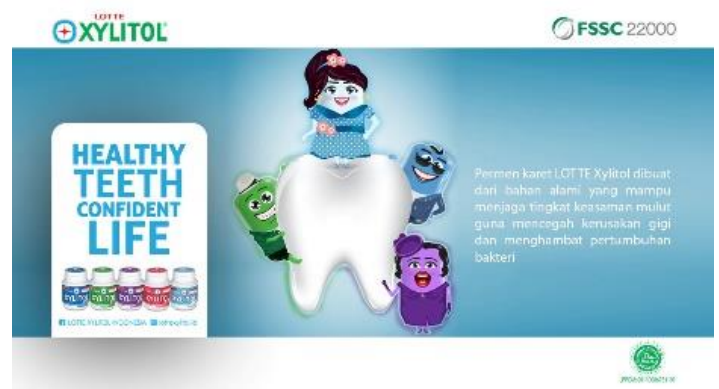

Gambar 2. Foto Produk Xylitol (Permen Karet)

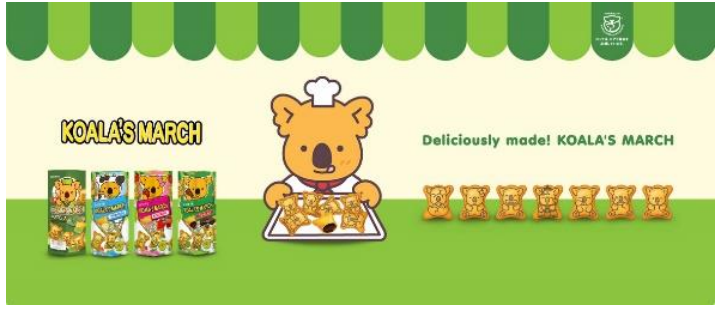

Gambar 3. Foto Produk Koala's March (Biskuit Bentuk Boneka)

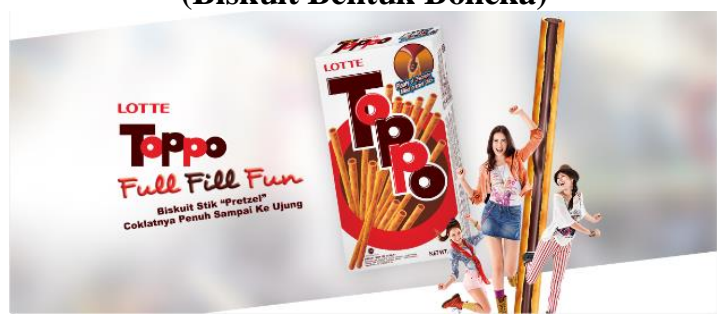

Gambar 4. Foto Produk Toppo (Biskuit Bentuk Stick)

Fungsi kehumasan perusahaan PT Lotte Indonesia dijalankan oleh Manajer Marketing. Manajer Marketing ini juga membawahi Departemen Sales atau Penjualan, sehingga aktivitas Marketing di perusahaan ini tidak berfokus hanya pada "business to business" saja tapi juga bauran aktivitas public relations atau kehumasan lainnya. Marketing Manager bertanggung jawab langsung kepada General Manager Lotte dari Jepang yaitu Yusuke Kawabata, sehingga posisi kehumasan termasuk sesuai dengan kaidah ilmu humas di jajaran pengelola perusahaan tertinggi walau atas nama departemen Marketing. 
Tabel 1. Struktur Organisasi PT Lotte Indonesia

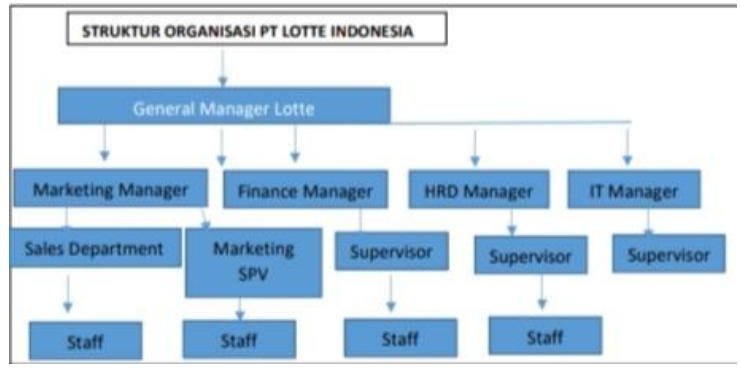

Berikut adalah hasil analisis SWOT untuk

PT Lotte Indonesia secara umum dan analisis SWOT Program Lotte Choco Pie Idol 2020 :

Tabel 2 Analisis SWOT PT Lotte Indonesia secara umum

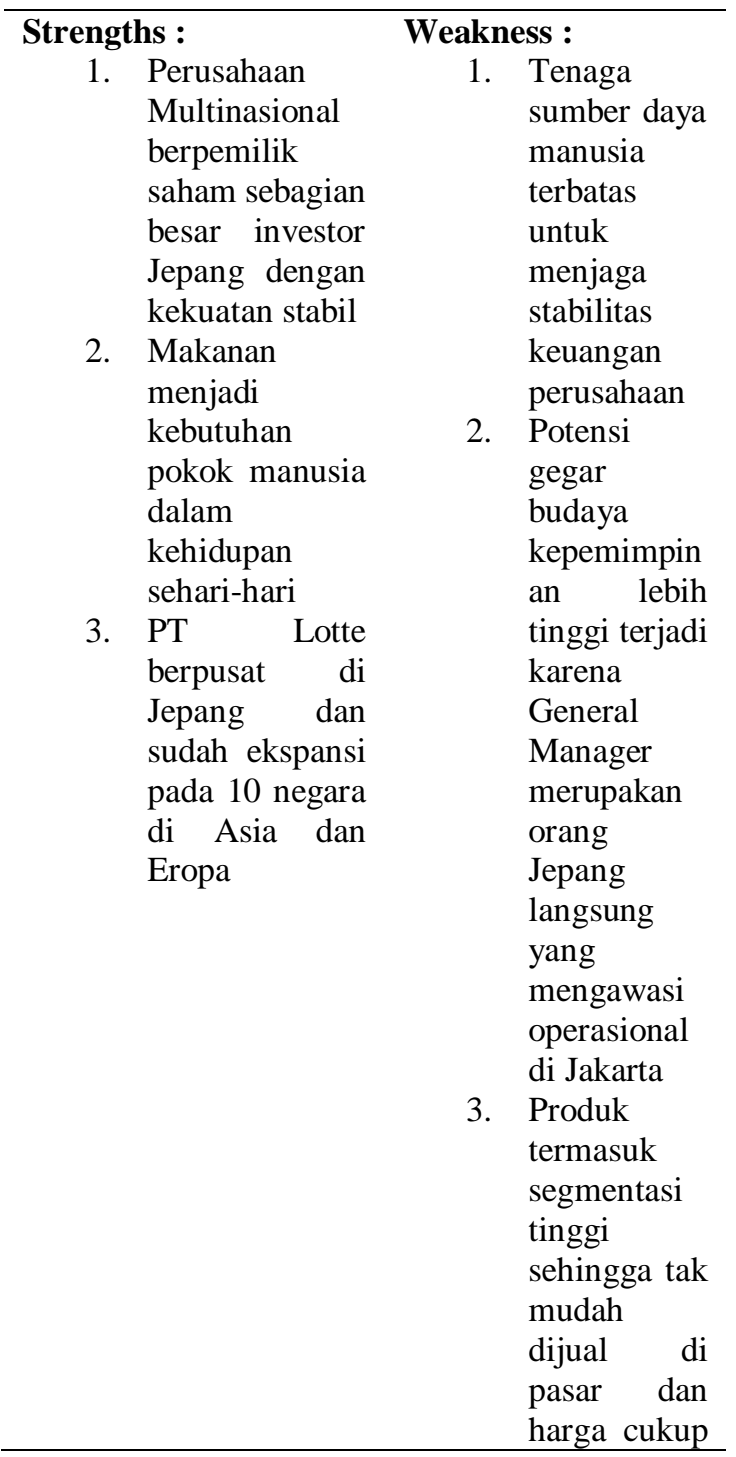

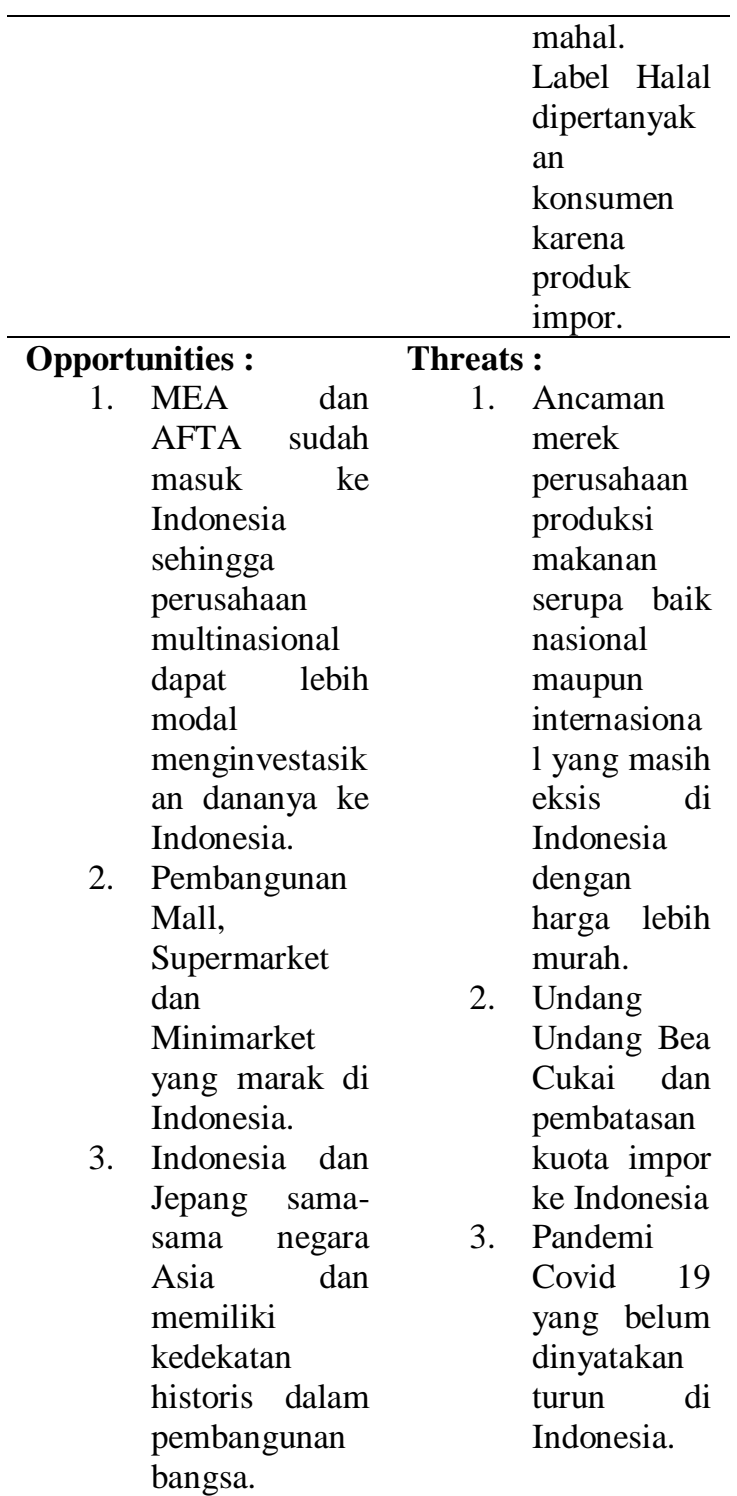

Tabel 3 Analisis SWOT Program Lotte Choco Pie Idol 2020

\begin{tabular}{cl}
\hline Strengths : & Weakness ; \\
1. & Dana \\
perusahaan & Pengelolaan \\
yang kuat & \multicolumn{2}{c}{ acara Lotte } \\
untuk & \multicolumn{2}{c}{ Choco Pie Idol } \\
membiayai & \multicolumn{2}{c}{ dan webinar } \\
tenaga & yang diserahkan \\
konsultan & secara 100 \\
humas & persen kepada \\
Jeune \& & konsultan \\
Raccord & humas atau \\
sebagai & agency \\
pihak & membuat \\
ketiga. & transparansi \\
Posisi & penilaian \\
Marketing & pemenang dan \\
Manager di & sosialisasi \\
bawah & identitas juri \\
langsung & sedikit \\
General & dipertanyakan \\
& masyarakat. \\
\hline
\end{tabular}




\begin{tabular}{|c|c|c|c|}
\hline 3. & $\begin{array}{l}\text { Manager } \\
\text { berdampak } \\
\text { pada } \\
\text { kemudahan } \\
\text { langsung } \\
\text { dalam akses } \\
\text { penyetujua } \\
\text { n dan } \\
\text { laporan } \\
\text { proposal } \\
\text { kegiatan. } \\
\text { Memiliki } \\
\text { tenaga } \\
\text { marketing } \\
\text { dan sales } \\
\text { yang handal } \\
\text { dalam latar } \\
\text { belakang } \\
\text { pendidikan } \\
\text { dan } \\
\text { keahlian } \\
\text { mencari } \\
\text { relasi. }\end{array}$ & 2. & $\begin{array}{l}\text { Pihak } \\
\text { manajerial PT } \\
\text { Lotte Indonesia } \\
\text { tidak terlibat } \\
\text { langsung } \\
\text { sebagai juri } \\
\text { dalam menilai } \\
\text { kontestan Lotte } \\
\text { Choco Pie Idol } \\
\text { 2020 menjadi } \\
\text { kurang objektif } \\
\text { untuk } \\
\text { merepresentasik } \\
\text { an citra merek } \\
\text { produk. } \\
\text { Biaya atau } \\
\text { anggaran yang } \\
\text { disediakan jauh } \\
\text { lebih mahal } \\
\text { karena } \\
\text { rancangan } 2 \\
\text { sistematika } \\
\text { antara online } \\
\text { dan offline, } \\
\text { sehingga harus } \\
\text { dana lebih } \\
\text { dalam persiapan } \\
\text { kuota internet, } \\
\text { perangkat } \\
\text { komputer dan } \\
\text { studio khusus } \\
\text { untuk menjamin } \\
\text { acara berjalan } \\
\text { optimal. }\end{array}$ \\
\hline 1. & $\begin{array}{l}\text { unities ; } \\
\text { Jumlah } \\
\text { penduduk } \\
\text { perempuan } \\
\text { di } \\
\text { Indonesia } \\
\text { lebih } \\
\text { banyak } \\
\text { dibandingk } \\
\text { an laki-laki } \\
\text { sehingga } \\
\text { potensi } \\
\text { yang } \\
\text { mempering } \\
\text { ati hari ibu } \\
\text { sebagai ibu } \\
\text { lebih besar. } \\
\text { Hasil } \\
\text { proyeksi } \\
\text { penduduk } \\
\text { Badan } \\
\text { Pusat } \\
\text { Statistik } \\
\text { (BPS) pada } \\
\text { tahun 2018 } \\
\text { menunjukk }\end{array}$ & $\begin{array}{c}\text { Threats } \\
1 .\end{array}$ & $\begin{array}{l}\text {; } \\
\text { referensimna lagu } \\
\text { anak-anak di era } \\
2010 \text { hingga } \\
\text { sekarang } \\
\text { menyebabkan } \\
\text { mati surinya } \\
\text { penyanyi cilik } \\
\text { Indonesia } \\
\text { dengan karakter } \\
\text { lagu anak. } \\
\text { Menyanyi } \\
\text { masih dianggap } \\
\text { sebagian } \\
\text { masyarakat } \\
\text { Indonesia } \\
\text { sebagai keahlian } \\
\text { yang tak } \\
\text { menjanjikan } \\
\text { masa depan } \\
\text { sehingga } \\
\text { sekolah vokasi } \\
\text { menyanyi dan } \\
\text { tari masih sepi } \\
\text { peminat. }\end{array}$ \\
\hline
\end{tabular}

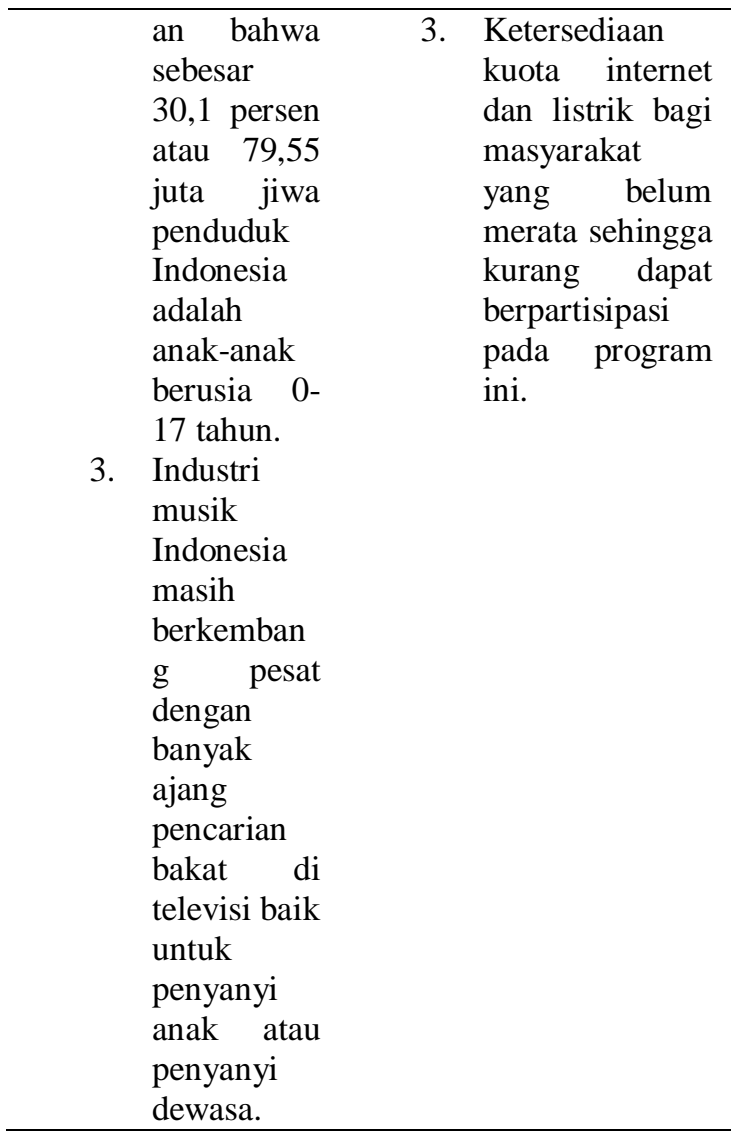

Berdasarkan hasil wawancara dengan key informan, Ingen Ate Malem Meliala sebagai Marketing Manager PT Lotte Indonesia, Special Event "Lotte Choco Pie Idol 2020" ini diadakan untuk menyampaikan pesan tentang pentingnya membangun kedekatan hubungan antara ibu dan anak setiap saat. Lotte Choco Pie secara konsisten menunjukkan kehadirannya selalu dinantikan di rumah untuk mewarnai harmonisasi keluarga Indonesia. Selain itu, pentingnya peran orang tua untuk mengenali potensi anak dan mengembangkannnya di jalur yang tepat.

Berdasarkan hasil wawancara dengan Informan 1 yaitu Indah Permata Sari sebagai konsumen dan peserta 
webinar, acara khusus atau special event yang dilakukan PT Lotte Indonesia sangat menarik dan bervariasi dilakukan dari tahun ke tahun. Apalagi dengan tema webinar pada tahun 2020 ini sangat memberikan manfaat edukasi bagi ibu rumah tangga sepertinya. Selama ini, masih banyak ditemukan orang tua yang memaksakan kehendaknya terhadap cita-cita dan bakat anak. Sementara, manusia itu sendiri memiliki 8 jenis kecerdasan yang berbeda dan tak dapat digeneralisasikan satu dengan lainnya. Ada anak yang dominan dalam kecerdasan matematis, ada yang dominan pada kecerdasan kinesik, figural, kecerdasan verbal dan seni. Selain itu, Indah Permata Sari mengungkapkan kegembiraan dan rasa syukurnya atas hadiah door prize yang diperoleh saat mengikuti webinar. Menurutnya, ini taktik baik bagi PT Lotte untuk membina hubungan baik dengan konsumennya.

Hasil wawancara dengan Informan 2 yaitu Laila Zahira juga menunjukkan apresiasi dan manfaat yang dilakukan PT Lotte untuk mengedukasi ibu dalam mendidik anak. Laila menilai produk lotte choco pie memang begitu concern dalam menyampaikan pesan pentingnya kedekatan ibu dan anak. Momentumnya juga tepat yaitu ketika special event dilakukan mendekati perayaan hari Ibu. Laila yang merupakan Mahasiswi Sastra Arab Universitas Indonesia mengungkap serunya webinar tema psikolog ini walaupun dia belum menikah dan menjadi ibu sesungguhnya. Dia mengungkapkan begitu senang dapat hadir diantara kebanyakan peserta webinar adalah ibu rumah tangga atau ibu karir yang sudah mempunyai anak. Webinar pun diselingi dengan sajian penampilan 10 Finalis dari Choco Pie Idol 2020, yang membuat suasana tidak bosan dan cukup menghibur.

Hasil wawancara dengan key informan yaitu Ingen Ate Malem Meliala sebagai Marketing Manager PT Lotte Indonesia juga mengungkap bahwa pengadaan special event ini tak lepas dari bantuan oleh pihak ketiga sebagai konsultan public relations (agency dan event organizer) dari jasa Jeune \& Raccord. Strategi Marketing Public Relations yang diusung untuk merayakan hari ibu ini berdasarkan perundingan penilaian proposal antara PT Lotte Indonesia dengan Jeune \& Raccord adalah Strategi Menarik (Pull Strategy) dan Strategi Melewati (Pass Strategy).

Ingen menyatakan alasan memilih kedua strategi itu karena PT Lotte Indonesia tidak ingin hanya menghamburkan uang dalam mengadakan special event tapi kebermanfaatan bagi umat dan nuansa amal serta edukasinya tidak tersampaikan kepada stakeholders. Selain itu, Strategi Mendorong (Push Strategy) itu sendiri sudah dijalankan oleh 
Departemen Sales melalui kerjasama dengan toko dan distributor. Ingen juga menambahkan bahwa implementasi special event ini juga berusaha untuk memenuhi konsep bauran Public Relations yang diungkapkan Kotler dalam ruang lingkup PENCILS yaitu Publication, Event, News, Community Involvement, Inform or image, Lobby or Negotiation dan Social Responsibility.

Pada level Publication, PT Lotte Indonesia telah mempublikasikan "special event"ini melalui berbagai media yang dimiliki, diantaranya media sosial facebook dan instagram. Adapun bentuk publikasi itu sebagai berikut:

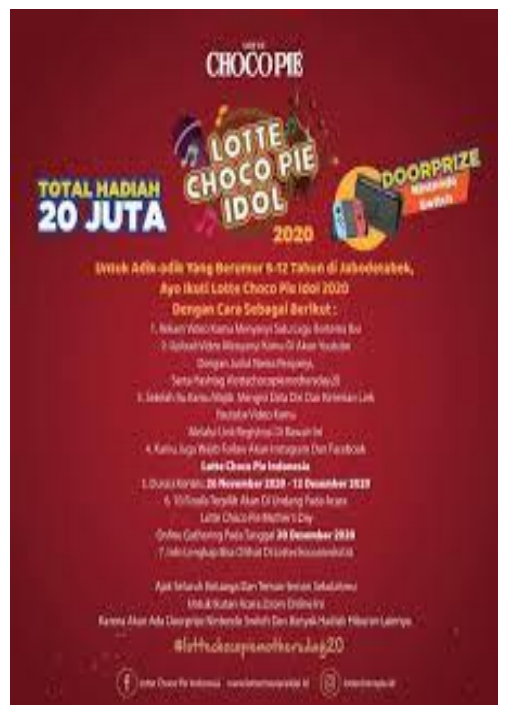

Gambar 5 Foto Sosialisasi Program Lotte Choco Pie Idol 2020 di Media Sosial Lotte Indonesia

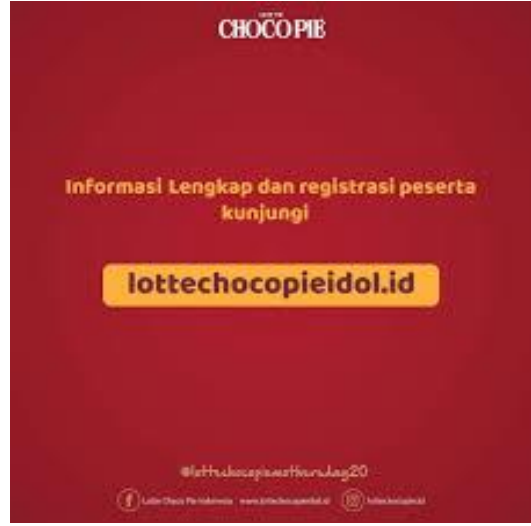

Gambar 6 Foto Sosialisasi Program Lotte Choco Pie Idol 2020 Part 2 di Media Sosial Lotte Indonesia

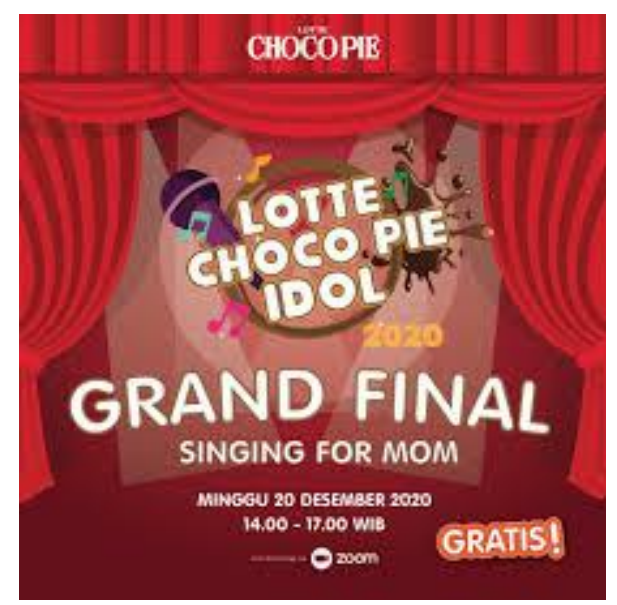

Gambar 7 Foto Sosialisasi Grand Final Lotte Choco Pie Idol 2020 Part 1

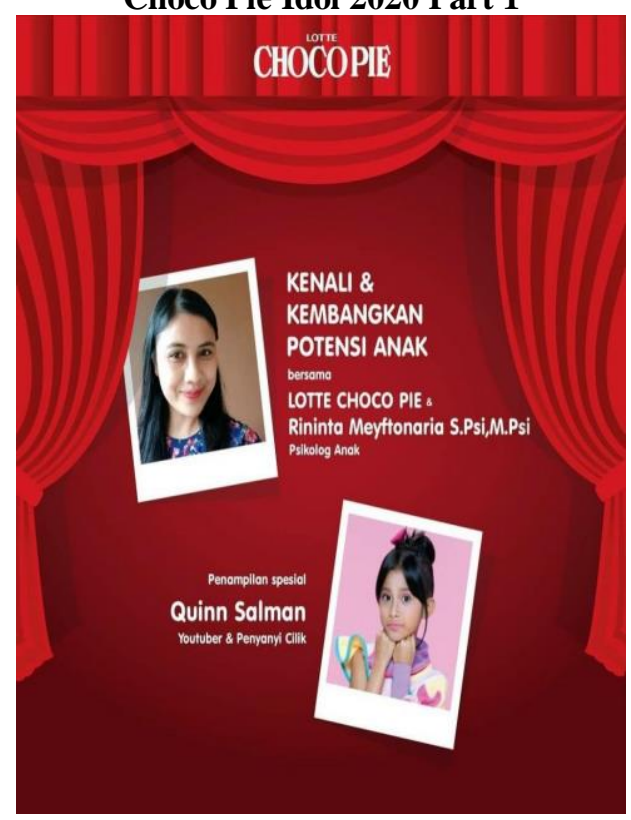

Gambar 8 Foto Sosialisasi Grand Final Lotte Choco Pie Idol 2020 Part 2 
Pada level Event, PT Lotte Indonesia mengadakan acara khusus yaitu Kegiatan festival berupa Lotte Choco Pie Idol 2020 dan kegiatan seminar berupa webinar tentang kenali diri dan potensi anak yang dibawakan oleh narasumber psikolog anak yaitu Ibu Rininta Meyftonaria melalui aplikasi zoom conference pada 20 Desember 2020. Adapun dokumentasi kegiatan terlampir berikut:

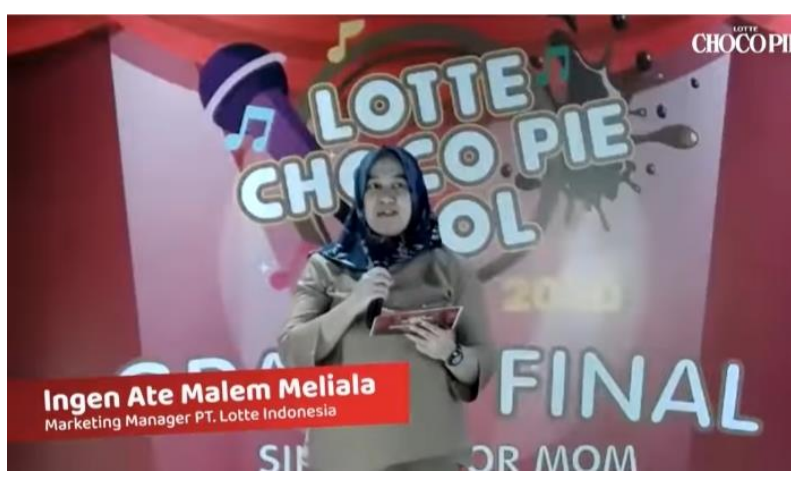

Gambar 9. Foto Ingen Ate Malem Meliala sebagai Marketing Manager PT Lotte Indonesia sedang memberikan sambutan di acara Grand Final Lotte Choco Pie Idol 2020 pada (20/12/2020)

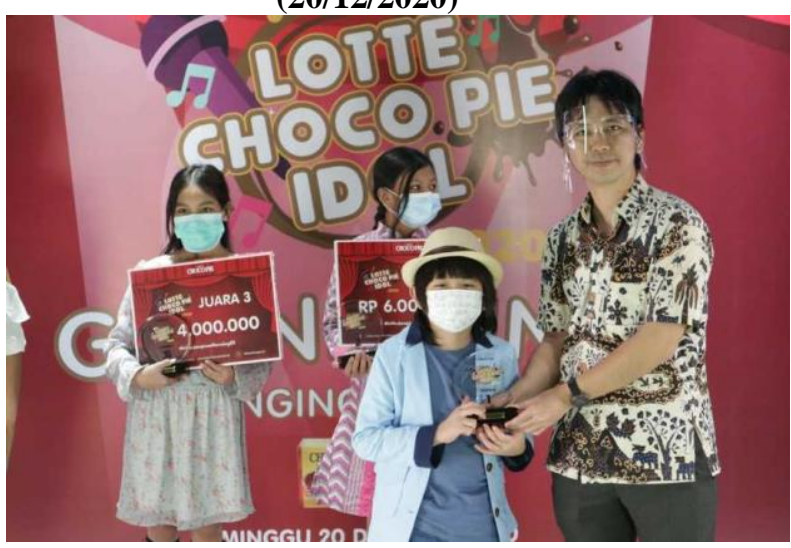

Gambar 10. Foto Penyerahan Thropy kepada Pemenang 1 Lawrence dari General Manager PT Lotte yaitu Yusuke Kawabata Pada $(20 / 12 / 2020)$.

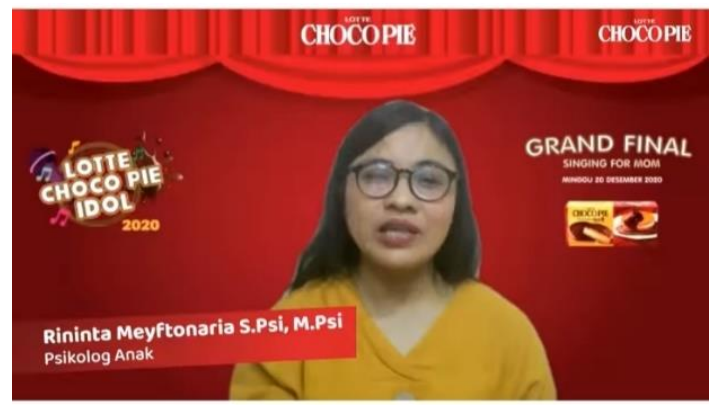

Gambar 11. Foto Psikolog Anak Rininta

Meyftonaria sedang memaparkan materi saat webinar di grand final Lotte Choco Pie Idol 2020 pada $(20 / 12 / 2020)$

Pada level News, PT Lotte Indonesia juga telah menulis press release seperti yang terpublikasi juga di media instagram@lottechocopie.id dan juga beberapa media massa yang mempublisitaskan special event ini seperti warta kota,berita satu dan idn times. Adapun link berita yang dapat diakses seperti terlampir berikut:

https://www.idntimes.com/hype/entertainm ent/ester-ajeng-2/lotte-choco-pie-idolmencari-bintang-cilik-di-tengah-pandemicsc

https://wartakota.tribunnews.com/2020/12 /21/rayakan-hari-ibu-lotte-choco-pie-idolmencari-bintang-cilik-di-tengah-pandemi

Pada level Community Involvement, PT Lotte Indonesia juga melalui special event ini berhasil untuk mendekatkan diri pada komunitas youtuber anak-anak dan ibu-ibu serta komunitas psikolog. Hal itu dibuktikan dengan mengundang psikolog dan youtuber anak pada acara grand final yang diadakan pada 20 Desember 2020 di 
Kantor MarkPlus Inc yang berlokasi di Kota Kasablanka, Lantai 10, Kuningan, Jakarta Selatan.

Pada level Inform or image, PT Lotte Indonesia juga berhasil menyampaikan citra yang baik kepada stakeholders. Hal itu terbukti pada hasil wawancara penulis kepada informan 1 dan informan 2 dalam penelitian ini, yang sudah penulis jelaskan sebelumnya. Selain itu, kegiatan pemilihan Choco Pie Idol 2020 ini juga mendapat sambutan positif bagi pengamat musik Indonesia seperti yang terlampir pada link berita berikut:

https://www.brilio.net/musik/nih-3-juara-

kompetisi-bintang-cilik-lotte-choco-pie-

idol-2020--201220n.html

Pada level Lobby and Negotiation, PT Lotte Indonesia melalui Choco Pie Idol 2020 telah berhasil melakukan lobi dan negosiasi pada Jeune \& Raccord yang ditunjuk sebagai pihak ketiga sebagai konsultan humas atau agency yang turut mendukung sukses penyelenggaraan special event ini. Selain itu, PT Lotte Indonesia berhasil melakukan lobi dan negosiasi pada pengamat musik serta pakar musik yang terlibat sebagai juri dalam kompetisi ini, kemudian pada youtuber anak yang hadir sebagai bintang tamu yaitu Quinn Salman serta Psikolog Rininta Meyftonaria.

Pada level Social Responsibility, PT

Lotte Indonesia juga berhasil dalam mengadakan webinar edukasi secara gratis kepada komunitas ibu-ibu agar lebih paham dalam mengedukasi anak. Selain itu, memberikan bekal kepada ibu-ibu agar dapat mengenali potensi anak dan mengembangkannya di jalur yang tepat. Pemberian hadiah dengan jumlah besar kepada 3 pemenang di Pemilihan Choco Pie Idol 2020, yaitu Juara 1 sebesar Rp. 10.000.000 dan single terbaru, Juara 2 sebesar Rp 6.000.000 dan Juara 3 sebesar Rp 4.000.000, juga disinyalir sebagai bentuk Social Responsibility PT Lotte Indonesia dalam mengembangkan bakat anak Indonesia sebagai penyanyi.

Berdasarkan analisis SWOT dan analisis teori PENCILS yang sudah penulis lakukan maka hasil penelitian menunjukkan bahwa PT Lotte Indonesia berhasil mengadakan special event dalam memperingati hari ibu melalui pemilihan Choco Pie Idol 2020. Strategi Marketing Public Relations yang dipilih oleh PT Lotte Indonesia adalah Pull Strategy dan Pass Strategy.

\section{Pull Strategy (Strategi} Menarik) yaitu strategi yang menarik dan dianggap menghabiskan banyak uang untuk periklanan dan promosi kepada konsumen, untuk membangun permintaan kepada konsumen. Jenis Strategi ini dipilih PT Lotte Indonesia melalui implementasi 
pengadaan special event Pemilihan

Choco Pie Idol 2020 yang menghabiskan anggaran tidak sedikit.

\section{Pass Strategy (Strategi}

Melewati) yaitu strategi alternatif yang dipilih pemasar dengan kombinasi upaya pendekatan dengan pemuka publik dan investasi sosial atau bakti sosial. Strategi ini juga dipilih PT Lotte Indonesia dengan pengadaan webinar gratis tentang edukasi psikologis kepada komunitas ibuibu agar lebih mengenali dan memahami potensi atau bakat anak dan mengembangkannya di jalur yang tepat.

\section{KESIMPULAN}

Special Event yang dilakukan PT Lotte Indonesia dalam memperingati hari ibu melalui Lotte Choco Pie Idol 2020 ini dapat dikatakan cukup berhasil. Strategi Marketing Public Relations yang dipilih oleh PT Lotte Indonesia adalah Pull Strategy dan Pass Strategy.

Saran yang dapat diajukan penulis kepada PT Lotte Indonesia agar meningkatkan gaung acara ini di tahun berikutnya dengan pembukaan peserta dalam skala nasional, bukan hanya wilayah jabodetabek saja agar gengsi kompetisi dapat lebih tinggi lagi diperkenalkan pada masyarakat dan konsumen.

\section{DAFTAR PUSTAKA}

Ali, D. S. F. (2017). Marketing Public Relations: Diantara Penjualan dan Pencitraan. Yogyakarta: Deepublish. Arifin, M. (2017). Strategi Manajemen Perubahan Dalam Meningkatkan Disiplin Di Perguruan Tinggi. Jurnal Ilmu Pendidikan Dan Ilmu Sosial, 3(1), 117-132. Retrieved from http://jurnal.umsu.ac.id/index.php/edu tech/article/view/990

Faradina, N. (2016). Penerimaan Diri Pada Orang Tua Yang Memiliki Anak Berkebutuhan Khusus. Jurnal Psikoborneo, 4(1), 18-23. Retrieved from http://ejournals.unmul.ac.id/index.php/psiko neo/article/view/3925

Harris, T. L. (2016). The Marketer's Guide to Public Relations in the 21st Century. Canada: Toronto Public Library.

Hartono, N.A., Dida, S., dan Hafiar, H. (2017). Pelaksanaan Kegiatan Special Event Jakarta Goes Pink Oleh Lovepink Indonesia. Jurnal Komunikasi, 10(2), 161. Retrieved from https://doi.org/10.21107/ilkom.v10i2. 2519

Hidayat, T. (2015). Pengaruh Marketing Public Relation Terhadap Loyalitas Pelanggan Pada PT Jalur Nugraha Ekakurir (JNE) Bandung. Jurnal Ekonomi, Bisnis, \& Entrepreneurship, 9(2), 102-115. Retrieved from http://jurnal.stiepas.ac.id/index.php/je be/article/view/115

Ihsan, R. dan A. (2018). Strategi Marketing Public Relations Lembaga Amil Zakat dalam Menarik Donatur Berdonasi. 3, 1-24.

Linawarti, M., D. (2016). Studi Deskriptif Pelatihan dan Pengembangan Sumber 
Daya Manusia serta Penggunaan Metode Behavioral Event Interview dalam Merekrut Karyawan Baru di Bank Mega Cabang Kudus. Journal of Management, 2(2), 1-8. Retrieved from http://jurnal.unpand.ac.id/index.php/ MS/article/view/604/588

Maulana, H. (2018). Pengembangan Jiwa Kewirausahaan : Studi Kasus terhadap Mahasiswa yang Berwirausaha di Yogyakarta. Jurnal Ecodemica, 2(1), 21-129. Retrieved from https://ejournal.bsi.ac.id/ejurnal/index .php/ecodemica/article/view/2666 Mayasari, S., Purihastine, M., dan Qibtiah, A. (2019). Strategi Public Relations PT Kasoem Hearing Dalam Mempublikasikan Kasoem Exhibition 2018 Kepada Masyarakat Indonesia. Jurnal Komunikasi, 10(1), 56-63. Retrieved from https://doi.org/10.31294/jkom.v10il.5 094

Moleong, L. J. (2011). Metodologi Penelitian Kualitatif Edisi Revisi. Bandung: PT Remaja Rosdakarya. Ruslan, R. (2012). Manajemen Public Relations dan Media Komunikasi: Konsepsi dan Aplikasi. Jakarta: PT Raja Grafindo Persada.

Soemirat, S. dan Ardianto, E. (2016). DASAR-DASAR PUBLIC RELATION (10th ed.). Bandung: PT Remaja Rosdakarya.

Sondak, Sandi Hesti, Rita, N, dan Y. U. (2019). Faktor-Faktor Loyalitas Pegawai di Dinas Pendidikan Daerah Provinsi Sulawesi Utara. Jurnal Emba Jurnal Riset Ekonomi, Manajemen, Bisnis, Dan Akuntansi, 7(1), 671-680. Retrieved from https://ejournal.unsrat.ac.id/index.php /emba/article/view/22478

Trisnawati, A. dan Syarah, M. M. (2017). Strategi Humas Politeknik Negeri Jakarta Dalam Penerimaan Mahasiswa Baru. Jurnal Komunikasi, 8(1), 92. Retrieved from
https://doi.org/10.31294/JKOM.V811 .2334.G1609

Udang, P., Pt, B., Mina, M., Aurora, N., Mustika, P.T., Nusa, M., Tarakan, A., dan Borneo, N. (2015). Analisis SWOT Dalam Menentukan Strategi Tarakan, Kalimantan Utara SWOT. Analysis in Determining The Marketing Strategy Of Frozen, 4(1), 60-67.

Virganantie, S. (2017). Evaluasi Special Event Temu Pelanggan di PT Jasa Marga (Persero), Tbk Cabang Surabaya - Gempol. Jurnal Komunikasi, 5(2), 1-11. Retrieved from http://publication.petra.ac.id/index.ph p/ilmukomunikasi/article/view/7082/6432

\section{Sumber Lain:}

https://www.kemenpppa.go.id/lib/uploads/slid er/e56dc-15242-profil-anak-indonesia_2019.pdf 